\title{
Effect of coriander (Coriandrum sativum L.) seed powder as feed additives on performance and some blood parameters of broiler chickens
}

\author{
Mona M. Khubeiz ${ }^{1,2^{*}}$ and Abdelfettah M. Shirif ${ }^{2}$ \\ ${ }^{1}$ Environment Public Authority, Tripoli, Libya \\ ${ }^{2}$ Department of Physiology, Biochemistry and Nutrition, Faculty of Veterinary Medicine, \\ University of Tripoli, Tripoli, Libya
}

\begin{abstract}
Background: Modern intensive poultry production has achieved phenomenal improvement in order to produce high quality chickens by the removal of antibiotics as growth promoters from poultry diets. Instead, numerous additives, such as probiotics, prebiotics, organic acids, enzymes, and phytogenics, are extensively used in poultry feed.

Aim: This study was conducted to investigate the effect of different levels of coriander (Coriandrum sativum) seed powder as a growth promoter on feed intake (FI), live body weight, weight gain, feed conversion ratio, carcass yield, and blood profile in broiler chickens.

Method: A total of 240 (Ross 308) one-day-old broiler chicks of mixed sexes were allocated randomly into four treatment groups, with 60 chicks per group. Each treatment group had three replicates (20 chicks per replicate), according to a completely randomized design for 45 days. The chicks were fed diets containing $0 \%$ (T1) as control, $1.5 \%$ (T2), $2.5 \%$ (T3), and 3.5\% (T4) of coriander seed powder. The FI, live body weight, and weight gain were monitored and measured on a weekly basis. Blood samples were collected on day 45 of the trial for the determination of the percentage of white blood cells and to assess the blood profile.

Results: It was revealed that the growth performance was not significantly affected $(p>0.05)$. However, the dressing percentage without the skin was significantly increased $(p<0.05)$ at level $1.5 \%$, while the heart weight was significantly augmented $(p<0.05)$ at $2.5 \%$, when compared to the control group. Furthermore, the serum triglyceride was significantly reduced $(p<0.05)$ at $1.5 \%$, while the high-density lipoprotein was significantly increased $(p<0.001)$ at level $1.5 \%$ when compared with the control and $3.5 \%$ groups. Moreover, the glutamic oxaloacetate transaminase and glutamate pyruvate transaminase were significantly increased at 3.5\% when compared with the control and $1.5 \%$ groups, with $p<0.01$ and $p<0.05$, respectively. The basophil and eosinophil cells count were significantly increased at $2.5 \%(p<0.05$ and $p<0.01)$, respectively, while the lymphocyte cell was significantly increased at $1.5 \%(p<0.01)$. Nevertheless, the heterophil cell and $\mathrm{H} / \mathrm{L}$ were significantly reduced at $1.5 \%(p<0.05)$.

Conclusion: Based on the results of this study, the inclusion of coriander seed powder at $1.5 \%$ had a positive impact on the dressing percentage without skin, biochemical blood profile, and immune response.

Keywords: Blood parameter, Broiler chicken, Coriander, Performance.

\section{Introduction}

The use of aromatic plants has been an important part of achieving modern intensive poultry production (Ghazanfari et al., 2015), due to their multiple positive effects on the health (Hashemi and Davoodi, 2010) through stimulation of appetite and feed intake (FI), the improvement of digestive enzyme secretion, activation of immune response (Rahimi et al., 2011), antibacterial properties (Patel and Vakilwala, 2016; Sambasivaraju and Fazeel, 2018), and antioxidant activity (Pathak et $a l ., 2011)$. Phytogenics have been used as flavors, food preservatives, and medicines (Applegate et al., 2010). Coriander (Coriandrum sativum L.) is a member of the Apiaceae family, native to the eastern Mediterranean region and southern Europe, and it is regarded as both herb and spice and reputedly has health advantages (Zeb,

2016). It has been used in medicine for thousands of years (Nadeem et al., 2013). Certain parts of this plant, such as the leaves, flowers, seeds, and fruits, are rich in beneficial phytonutrients, including linalool (67.6\%), which is an important one, monoterpene alcohol, camphor $(4.4 \%), \alpha$-pinene $(7.1 \%)$, and terpinene gamma by the manufacturing company Hamodi et al. (2010). Linalool essential oils possess anthelmintic, antifungal, antioxidant, antimicrobial properties (Silva et al., 2011; Saleh et al., 2014). Furthermore, it has an appetizing and stimulatory effect in the digestion process, which improves the growth performance. The aim of this study was to investigate the effect of the application of different levels of coriander seeds on the performance, hemato-biochemical, and immune responses of broiler chickens.
\end{abstract}




\section{Material and Methods}

\section{Chicks and experimental designs}

A trial was carried out at the Medical Clinic, Department of Physiology, Biochemistry and Nutrition, Faculty of Veterinary Medicine, University of Tripoli. The trial was designed according to a completely randomized design. A total of 240 1-day-old broiler chickens of mixed sexes of the commercial Ross 308 strain were used in this study. The initial body weight of each chick was taken, recorded, and randomly allocated into four treatment groups 2 days after the chicks arrived, known as the acclimatization period. Each treatment group comprised 60 chicks distributed into three replicates, where each replicate involved 20 chicks, having an equal number of both sexes, reared in clean pens fitted with deep litter under a standard hygienic condition for 45 days.

\section{Diets and husbandry}

Two experimental diets (starter and finisher) were used in this trial. They were set by Al-Maraie Company according to the National Research Council (NRC) regulations (1994) and standard to meet the chickens' daily requirements. The ingredients and chemical composition of the experimental diets are presented in Table 1. The chicks were fed a starter diet for the first 18 days, followed by a finisher diet for the rest of the trial (18-45 days). The coriander seeds were passed through a 2-mm sieve hammer mill and placed into labeled plastic bags and mixed with the basal diets at the rate of $0 \%$ (T1) as control, with no supplement, 1.5\% (T2: $150 \mathrm{~g}$ coriander plus $9.850 \mathrm{~kg}$ of basal diet in total mixture of $10 \mathrm{~kg}$ ), $2.5 \%$ (T3: $250 \mathrm{~g}$ coriander plus $9.750 \mathrm{~kg}$ of basal diet in total mixture of $10 \mathrm{~kg}$ ), and $3.5 \%$ (T4: 350 $\mathrm{g}$ coriander plus $9.650 \mathrm{~kg}$ of basal diet in total mixture of $10 \mathrm{~kg}$ ) using an electric concrete mixing machine. At the same time, a small portion of crude coriander seed powder was kept in an airtight, labeled dark glass container and used for chemical analysis. The dry matter (DM), organic matter (OM), ether extract (EE), and crude protein $(\mathrm{CP})$ were determined according to the methods of AOAC (1990). Due to the importance of lignin as an "antinutritive value" in poultry diet, the nutrient detergent fiber (NDF), acid detergent fiber (ADF), and acid detergent lignin (ADL) were analyzed as described by Goering and van Soest (1970). Hemicellulose and cellulose were calculated from the data of NDF, ADF, and ADL as suggested by van Soest et al. (1991) (Table 2). The experimental room was divided into 12 equalsized individual pens $(1 \times 1.1 \mathrm{~m})$ separated by metal mesh partitions, according to the treatment levels and replicates. Twenty chicks were housed in each treatment replicate pen, according to the density standard of rearing $10 \mathrm{birds} / \mathrm{m}^{2}$. Each pen was provided with a trough and water bucket, and wood shavings were used as litter material. The chicks had free access to feeds and water (ad libitum). The ambient temperature was initially set at $32^{\circ} \mathrm{C}$ for the first 7 days and then gradually reduced to $24^{\circ} \mathrm{C}$ on day 21 and kept constant for the rest of the trial. Photoperiods were set for 24 hours/days for the
Table 1. Ingredients, chemical analyses, and composition of the starter and finisher diets.

\begin{tabular}{lcc}
\hline Ingredients (kg/1,000 kg) & Starter & Finisher \\
\hline Yelow corn & 470 & 522 \\
Wheat & 150 & 150 \\
\hline Soyabean (cp47\%) & 322 & 265 \\
Corn oil & 10 & 15 \\
\hline Ground limestone & 7.2 & 7.2 \\
\hline Salt & 2.8 & 2.8 \\
\hline Vitamin and mineral premix & 38 & 38 \\
\hline Total & 1,000 & 1,000 \\
\hline Calculatedc chemical analysis (\%) & & \\
\hline Metabolizable energy (ME) & 2,930 & 2,996 \\
\hline CP & 21.6 & 20 \\
EE & 3 & 3 \\
\hline Crude fiber (CF) & 3 & 3 \\
\hline Calcium & 1 & 1 \\
\hline P(available) & 0.4 & 0.40 \\
\hline Lysin & 1.25 & 1 \\
\hline Methionin & 0.50 & 0.46 \\
\hline Threonine & 0.76 & 0.64 \\
\hline Tryptophan & 0.25 & 0.23 \\
Argenin & 1.42 & 1.29 \\
\hline Valin & 1.08 & 0.99 \\
\hline All comp & & \\
\hline
\end{tabular}

All components are in percentage, except ME is expressed in kcal/ $\mathrm{kg}$. Vitamin and Mineral premix per kg of starter diet: vitamin a, 1,400 IU; Vitamin D, 3,000 IU; vitamin E, $30 \mathrm{mg}$; vitamin $\mathrm{B}_{1} 2.8$ $\mathrm{mg}$; vitamin $\mathrm{B}_{2}, 5 \mathrm{mg}$; Vitamin $\mathrm{B}_{3}, 40 \mathrm{mg}$; Vitamin $\mathrm{B}_{5}$; 12, Vitamin $\mathrm{B}_{6} 4 \mathrm{mg}$, folic acid, $1 \mathrm{mg}$; Manganese, $80 \mathrm{mg}$, Selenium, 0.3, Iron, 50, Copper, 10, Zink, 80, Phosphorous Phytase, 500 FTU, Anticoccidioses, $500 \mathrm{mg}$. Vitamin and Mineral premix per $\mathrm{kg}$ of finisher diet: vitamin a, 1,200 IU; Vitamin D, 3,000 IU; vitamin E, $30 \mathrm{mg}$; vitamin $\mathrm{B}_{1}, 2.8 \mathrm{mg}$; vitamin, $3 \mathrm{mg}$; Vitamin $\mathrm{B}_{3}, 40 \mathrm{mg}$; Vitamin $\mathrm{B}_{5}$; 10, Vitamin $\mathrm{B}_{6} 4 \mathrm{mg}$, folic acid, $1 \mathrm{mg}$; Manganese, $80 \mathrm{mg}$ Selenium, 0.3, Iron, 50, Copper, 10, Zink, 80, Phosphorous Phytase, 1,000 FTU, Anticoccidioses, 500 mg.

first week and reduced to 23 hours/days for the rest of the trial. The chicks were vaccinated against infectious bronchitis (1st and 16th day of age), Newcastle disease (1st, 8th, and 20th day of age), and infectious bursal disease (Gumboro) (12th day of age).

\section{Performance parameters}

During the rearing period, FI and individual body weights were monitored on a weekly basis per pen. On the other hand, the body weight gain (BWG) and feed conversion ratio (FCR) were consequently calculated. Mortality of birds was also recorded on a daily basis for each group. At the end of the experiment, the dressing percentage was estimated by randomly selecting five chickens from every replicate for each treatment level; they were weighed, recorded, and sacrificed according 
to the Islamic way, by severing the right and left carotids and jugular vessels, trachea, and esophagus. Generally, the carcass weight was recorded immediately after plucking or skinning and evisceration; this is commonly known as the hot hanging weight for determining carcass yield. After complete bleeding, two of the sacrificed chickens were scalded in hot water, hand plucked, washed, and reweighed, while the other three chickens from each replicate were skinned, weighed, and recorded. Then, the head was removed at a point close to the skull. Feet shanks were also removed at the hock joint and eviscerated characteristics for carcass was carried out (Rashid et al., 2014). The internal organs (heart, liver, proventriculus, and gizzard) were collected, weighed, and measured as well.

\section{Blood collection}

The blood samples were collected from three chickens of each replicate, in aggregate of nine chickens of each treatment that were randomly selected, labeled,

Table 2. The chemical composition $(\mathrm{g} / \mathrm{kg})$ of coriander seed powder.

\begin{tabular}{lc}
\hline Chemical composition & g/Kg DM \\
\hline DM & 929.8 \\
\hline OM & 862.3 \\
\hline Ash & 67.5 \\
\hline CP & 112.3 \\
\hline EE & 214.8 \\
\hline NDF & 762.5 \\
\hline ADF & 504.5 \\
\hline ADL & 165.0 \\
\hline Hemicellulose & 258.0 \\
\hline Cellulose & 339.0 \\
\hline
\end{tabular}

Amount (g/Kg, dry matter basis). and placed into separate cages and fasted overnight for blood sampling. The blood was withdrawn from the ulnar vein at the end of the trial. Blood samples were kept in two types of test tubes, where half of the sample was placed into anticoagulant tubes (EDTA tube $\mathrm{K}_{3}$ EDTA) and was used for measuring the white blood cell counts and the heterophil/lymphocyte (H/L) ratio as described by Shoukary et al. (2017), whereas the other half of the sample was collected into procoagulation clot activator tubes and centrifuged for 10 minutes at 3,000 rpm to obtain the serum and stored in the freezer at $-21^{\circ} \mathrm{C}$ for 24 hours. The samples were analyzed for glucose, total cholesterol, triglycerides (TG), high-density lipoprotein (HDL), and low-density lipoprotein (LDL) using specific kits (Ghazanfari et al., 2015), while the glutamic oxaloacetate transaminase (GOT) and glutamate pyruvate transaminase (GPT) were measured as described by Saleh et al. (2014).

\section{Statistical analysis}

The calculations and statistical analyses were carried out by using a spreadsheet (Microsoft Excel) and the Minitab software package, respectively. The analysis of variance was used for preliminary analysis of data by using the general linear model (procedure). Normality test was applied on all data residuals and all the variables passed this test $(p<0.01)$. Tukey's test was used for comparing the mean values of the variables.

Ethical approval

All applicable international and national guidelines for the care and use of animals were followed.

\section{Results}

\section{Growth performance}

The results showed that the supplementation of coriander seed powder at different levels had no significant effect $(p>0.05)$ on growth performance, as well as mortality rates, of the chickens during the experimental period (Table 3).

Table 3. Effect of coriander seed powder at different levels $(\mathrm{g} / \mathrm{kg} \mathrm{DM})$ on growth performance and mortality rate at different ages.

\begin{tabular}{|c|c|c|c|c|c|c|c|}
\hline \multirow{2}{*}{ Parameters } & \multirow{2}{*}{ Age(d) } & \multicolumn{4}{|c|}{ Levels of coriander } & \multirow{2}{*}{ SEM } & \multirow{2}{*}{ Significant } \\
\hline & & $0 \%$ & $1.5 \%$ & $2.5 \%$ & $3.5 \%$ & & \\
\hline \multirow{3}{*}{$\begin{array}{l}\text { Feed intake } \\
\text { (g/bird/week) }\end{array}$} & $1-7$ & 199.7 & 219.9 & 222.5 & 213.0 & 5.482 & NS \\
\hline & $15-21$ & 698.1 & 707.4 & 708.9 & 693.5 & 18.10 & NS \\
\hline & $29-35$ & $1,136.9$ & $1,111.3$ & $1,108.6$ & $1,084.4$ & 18.49 & NS \\
\hline Total feed intake & $1-42$ & $4,639.1$ & $4,648.8$ & $4,590.8$ & $4,607.3$ & 52.73 & NS \\
\hline \multirow{3}{*}{ Body weight (g/bird/week) } & 7 & 230 & 230 & 273 & 222 & 17.70 & NS \\
\hline & 21 & 1,077 & 1,087 & 1,089 & 1,056 & 21.29 & NS \\
\hline & 35 & 2,276 & 2,165 & 2,160 & 2,176 & 43.25 & NS \\
\hline BWG & $1-42$ & 2,835 & 2,744 & 2,697 & 2,700 & 51.58 & NS \\
\hline FCR & $1-42$ & 1.636 & 1.694 & 1.702 & 1.706 & 0.027 & NS \\
\hline Mortality rate & $1-42$ & 0.05 & 0.00 & 0.03 & 0.03 & 0.019 & NS \\
\hline
\end{tabular}

$\mathrm{NS}=$ not significant $p>0.05$; SEM $=$ stander error of mean. 


\section{Carcass yield}

The results in Table 4 show that the dressing percentage of the broiler chickens with skin did not show any significance changes $(p>0.05)$ in all treatments, when compared with the control group. Although a slight increase was observed at levels $1.5 \%$ and $3.5 \%$, it was not statistically important $(p>0.05)$. However, the dressing percentage without skin was significantly increased $(p<0.05)$ with the application of coriander at $1.5 \%$, when compared with the $2.5 \%$ group. The heart weights were significantly increased $(p<0.05)$ in the treatment diets, where the highest weight was observed at $2.5 \%$ when compared with the control group; in addition to that, the proventriculus weights were significantly increased $(p<0.05)$ in the treated diets, where the highest weight was observed at $1.5 \%$ when compared with the control group. However, the weights of the livers and gizzards were similar $(p>0.05)$ for all treatment groups during the whole trial.

\section{Blood analysis}

The effect of feeding different levels of coriander seed powder on biochemical and immune blood parameters of broilers showed that the concentrations of cholesterol were significantly increased $(p<0.01)$ when the chickens were fed a finished diet supplemented with $3.5 \%$ of coriander seeds powder when compared with the control group. However, the TG and GPT were significantly increased $(p<0.05)$ in the two treatment levels at $1.5 \%$ and $3.5 \%$, while the concentration of GOT was significantly increased $(p<0.01)$ when chickens received a basal diet supplemented with coriander seeds powder at 3.5\%. Moreover, the HDL was significantly increased $(p<0.001)$ when the chickens were fed a basal diet supplemented with coriander seeds powder at $1.5 \%$, while the concentration of LDL was significantly increased $(p<0.01)$ when the chickens received a basal diet supplemented with coriander seeds powder at 3.5\% when compared with the other two treatment $(1.5 \%$ and $2.5 \%$ ) groups. The percentage of heterophil cells and the $\mathrm{H} / \mathrm{L}$ ratio were significantly reduced $(p<0.05)$ when the diet was mixed with $1.5 \%$ coriander when compared with the control and the other two treatment $(2.5 \%$ and $3.5 \%)$ groups, whereas the highest mean values were reported in the control group. Nevertheless, the percentage of lymphocyte cells was significantly increased $(p<0.05)$ when the chickens fed on a diet supplemented with $1.5 \%$ of coriander seeds powder when compared with the control and the $2.5 \%$ groups. These results are summarized in Table 5.

\section{Discussion}

\section{Feed intake}

The FI was not affected by the three levels of coriander and these results were in agreement with other studies (Saeid and Al-nasr, 2010; Al-Jaff, 2011; Amad et al., 2011; Abadi and Andi, 2014; Abou-Elkhair et al., 2014; Rashid et al., 2014). This finding may be attributed to the chemical composition of the basal diets, which can be due to the fluctuation of the environmental temperature that reflected inside the room and relative humidity during the last couple of experiment weeks, which was confirmed by the thermostatic theory described by Ferket and Gernat (2006), who reported that the major environmental factor in controlling FI is ambient temperature, which leads to increased water consumption and in turn it decreases the FI. Brenes and Roura (2010) reported that decreased FI with no significant changes in BWG is probably due to reduced palatability of diet and the pungent odor of the phytogenic compounds. On the contrary, other studies have reported significant effects of coriander seeds on FI of broiler chickens (Hamodi et al., 2010; Al-Mashhadani et al., 2011; Esteghamat, 2014; Naeemasa et al., 2015; Hady et al., 2016). This effect can be attributed to the improvement of digestive enzymes, which are partially associated with an enhanced feed consumption, apparently due to an improved palatability of the diet and the presence of linalool (Applegate et al., 2010).

\section{Body weight}

In this study, the body weight and BWG had no significant effects with regard to the supplementation of coriander at different levels; however, these results

Table 4. Effect of coriander seed powder at different levels $(\mathrm{g} / \mathrm{kg} \mathrm{DM})$ on the dressing percentage and the internal organ weights (g).

\begin{tabular}{|c|c|c|c|c|c|c|}
\hline \multirow{2}{*}{ Dressing \% and internal organ } & \multicolumn{4}{|c|}{ Levels of Coriander } & \multirow{2}{*}{ SEM } & \multirow{2}{*}{ Significant } \\
\hline & $0 \%$ & $1.5 \%$ & $2.5 \%$ & $3.5 \%$ & & \\
\hline With skin & 76.71 & 78.78 & 73.85 & 78.39 & 3.19 & NS \\
\hline Without skin & 65. $0^{\mathrm{ab}}$ & $72.41^{\mathrm{a}}$ & $60.92^{\mathrm{b}}$ & $65.21^{\mathrm{ab}}$ & 2.80 & $*$ \\
\hline Heart & $11.26^{\mathrm{b}}$ & $13.10^{\mathrm{ab}}$ & $13.82^{\mathrm{a}}$ & $12.72^{\mathrm{ab}}$ & 0.61 & $*$ \\
\hline Liver & 58.54 & 60.59 & 58.14 & 56.32 & 3.10 & NS \\
\hline Gizzard + con & 56.44 & 55.13 & 64.36 & 56.94 & 2.60 & NS \\
\hline Gizzard - con. & 38.16 & 40.11 & 40.19 & 41.27 & 1.39 & NS \\
\hline Proventriculus + cont & $8.42^{\mathrm{b}}$ & $10.41^{\mathrm{a}}$ & $9.55^{\mathrm{ab}}$ & $9.38^{\mathrm{ab}}$ & 0.43 & $*$ \\
\hline Proventriculus - con & 8.17 & 9.32 & 9.35 & 9.16 & 0.36 & NS \\
\hline
\end{tabular}

Value with different superscripts in same rows indicated significance at $p<0.05\left(^{*}\right)$. NS $=$ not significant $p>0.05$; SEM $=$ stander error of mean 
Table 5. Effect of coriander seed powder at different levels $(\mathrm{g} / \mathrm{kg} \mathrm{DM})$ on the blood parameters and differentiation of white blood cells at the end of the trial.

\begin{tabular}{|c|c|c|c|c|c|c|}
\hline \multirow{2}{*}{ Blood biochemical parameter } & \multicolumn{4}{|c|}{ Levels of coriander } & \multirow{2}{*}{ SEM } & \multirow{2}{*}{ Significant } \\
\hline & $0 \%$ & $1.5 \%$ & $2.5 \%$ & $3.5 \%$ & & \\
\hline Glucose & 172.1 & 174.1 & 168.3 & 171.1 & 2.22 & NS \\
\hline Cholesterol & $91.89^{\mathrm{b}}$ & $104.6^{\mathrm{ab}}$ & $85.56^{\mathrm{b}}$ & $121.8^{\mathrm{a}}$ & 7.27 & $* *$ \\
\hline Triglycerides & $77.44^{\mathrm{ab}}$ & $69.33^{\mathrm{b}}$ & $76.50^{\mathrm{ab}}$ & $90.33^{\mathrm{a}}$ & 5.23 & $*$ \\
\hline LDL & $38.00^{\mathrm{ab}}$ & $33.24^{b}$ & $27.13^{b}$ & $67.41^{\mathrm{a}}$ & 8.05 & $* *$ \\
\hline HDL & $38.33^{\mathrm{b}}$ & $57.44^{\mathrm{a}}$ & $44.88^{\mathrm{ab}}$ & $36.21^{\mathrm{b}}$ & 3.72 & $* * *$ \\
\hline GOT & $205.9^{b}$ & $196.1^{\mathrm{b}}$ & $218.7^{\mathrm{ab}}$ & $273.1^{\mathrm{a}}$ & 15.69 & $* *$ \\
\hline GPT & $7.33^{\mathrm{ab}}$ & $6.33^{\mathrm{b}}$ & $7.33^{\mathrm{ab}}$ & $9.22^{\mathrm{a}}$ & 0.72 & $*$ \\
\hline \multicolumn{7}{|l|}{$\mathrm{WBC} \%$} \\
\hline Basophil & $3.6^{\mathrm{ab}}$ & $1.8^{\mathrm{b}}$ & $5.5^{\mathrm{a}}$ & $2.8^{\mathrm{ab}}$ & 0.96 & $*$ \\
\hline Eosinophil & $1.3^{\mathrm{b}}$ & $2.8^{\mathrm{b}}$ & $7.6^{\mathrm{a}}$ & $4.6^{\mathrm{ab}}$ & 1.09 & $* *$ \\
\hline Monocyte & 4.5 & 5.8 & 6.5 & 5.3 & 1.70 & NS \\
\hline Heterophil & $37.9^{\mathrm{a}}$ & $19.6^{\mathrm{b}}$ & $30.5^{\mathrm{ab}}$ & $30.2^{\mathrm{ab}}$ & 4.00 & $*$ \\
\hline Lymphocyte & $52.7^{\mathrm{b}}$ & $70.1^{\mathrm{a}}$ & $49.2^{\mathrm{b}}$ & $57.2^{\mathrm{ab}}$ & 4.51 & $*$ \\
\hline $\mathrm{H} / \mathrm{L}$ & $0.9^{\mathrm{a}}$ & $0.3 b$ & $0.7^{\mathrm{ab}}$ & $0.6^{\mathrm{ab}}$ & 0.157 & $*$ \\
\hline
\end{tabular}

Values with different superscripts in same rows indicated significance at $p<0.001(* * *), p<0.01(* *)$ and $p<0.05(*)$. NS $=$ not significant $p<$ $0.05 ; \mathrm{SEM}=$ stander error of mean. The units of glucose, cholesterol, triglycerides, LDL cholesterol and HDL cholesterol were measured in mg/ $\mathrm{dl}$, while glutamic oxaloacetic transaminase and glutamic pyruvate transaminase were measured in IU/L. (H/L) = Heterophil to Lymphocyte ratio.

correspond with other studies (Saeid and Al-nasr, 2010; Amad et al., 2011; Jang, 2011; Abadi and Andi, 2014). These results may be related to the antinutritional factors of natural compounds, such as lignin, trypsin, alkaloids, oxalates, phenolic, and phytates in the basal diets, which may reduce the digestibility, and subsequently, the absorption of other important nutrients that increase BW (Brenes and Roura, 2010), as well as the dependence on the applied dosage of the respective ingredients. On the contrary, the BW and BWG were significantly increased with the application of coriander seeds in chicken diets (Hamodi et al., 2010; Rashid et al., 2014), and this is probably due to the antibacterial properties, which act as natural growth promoters (Pathak et al., 2011).

\section{Feed conversion ratio}

According to the data obtained in this study, the FCR was not significantly affected with the supplementation of coriander, but it was related to the BWG and FI, which is in agreement with Saleh et al.'s (2014) and Barad et al.'s (2016) studies. This feature can also be related to environmental and genetic factors that influence the chemical composition of plant essential oils and their extracts, which also can be affected by the state of maturity of the plant on harvesting, as well as the conditions and the period of storage (Brenes and Roura, 2010; Shams et al., 2016). Other factors, such as insufficient levels of coriander seeds in the formulated diet, which have different essential oils in different parts of the world (Nadeem et al., 2013), agree with the previous reports by Misharina (2001), who reported that the content of essential oil of dried fruits varies from $0.03 \%$ to $2.6 \%$ depending on the species, growing region, and climatic conditions, which also explain the variability in the efficacy of EOs on animal performance. On the contrary, other studies have reported that the FCR was improved with the application of coriander seed powder in chicken diets (Hamodi et al., 2010; AlJaff, 2011; Farag, 2013), and this may be attributed to the significant increase in pancreatic amylase, trypsin, and maltase activities in broilers fed different blends of commercial EOs (Brenes and Roura, 2010).

\section{Carcass yield}

The findings correspond with other studies (Saeid and Al-nasr, 2010; Jang, 2011; Farag, 2013). The increase in dressing percentage without skin may be attributed to the stimulatory effects on pancreatic secretions that in turn may increase the secretions of digestive enzymes, which lead to more amounts of nutrients, such as amino acids, digested and absorbed from the digestive tract and hence improve carcass traits (Rahimi et al., 2011). Abo Omar et al. (2016) revealed that the presence of antioxidants and phenolic substance in herbal extract enhanced the carcass breast of broiler chicken by $1.2 \%$. Furthermore, the dressing percentage with skin in this trial was in agreement with other studies (Rashid et al., 2014; Naeemasa et al., 2015) which reported that the use of herbal plants had no effect on the dressing percentage of broiler chickens. However, the heart weights were significantly increased $(p<0.05)$ in 
treatment diets, where the highest weight was observed at $2.5 \%$ when compared with the control group. This is also in agreement with the findings of other studies (Naeemasa et al., 2015; Hady et al., 2016), which reported that the increase in heart, liver, and gizzard weights when the chickens fed on a diet supplemented with coriander extract at $101-625 \mathrm{mg} / \mathrm{kg}$ and coriander powder at $7.5 \mathrm{~g} / \mathrm{kg}$, respectively, can be related to the increases of cells proliferation of these organs compared with the control group. Moreover, the proventriculus weights were significantly increased $(p<0.05)$ in the treated diets, where the highest weight was observed at $1.5 \%$ when compared with the control group. This result is in agreement with Abou-Elkhair et al.'s (2014) study and in disagreement with Rahimi et al.'s (2011) study, which reported no significant difference in the weight of organs of broiler chickens.

\section{Blood analysis}

The mean values of serum glucose were unchanged ( $p$ $>0.05)$ when compared with the control group. These findings are in agreement with Abadi and Andi's (2014) study and in disagreement with Abou-Elkhair et al.'s (2014) study. On the contrary, the mean values of serum LDL and HDL were increased at $3.5 \%$ and $1.5 \%$ of coriander seed powder, respectively. The coriander oil interferes with the production of mevalonate by acting as a reversible competitive inhibitor of $\mathrm{HMG}-\mathrm{CoA}$ reductase enzyme, resulting in hypocholesterolemia (Dhanapakiam et al., 2007). With regard to GOT and GPT, which are considered as important liver enzymes, the concentration of GOT was significantly increased ( $p$ $<0.01)$ at $3.5 \%$ when compared with the control and $1.5 \%$ groups. In addition, the GPT was significantly increased $(p<0.05)$ at $3.5 \%$ when compared with the $1.5 \%$ group. These results are in agreement with the previous observations (Al-Jaff, 2011; Farag, 2013). Thus, the decrease in serum concentration of GOT and GPT may provide evidence for the occurrence of the hepatoprotective effect of coriander seed and its essential oil (Al-Jaff, 2011). Hence, the effect of feeding different levels of coriander powder, with the differentiation of white blood cells (WBC), was significantly different in chickens. The monocyte cells were not affected in this study, which is in agreement with Abadi and Andi's (2014) study and in disagreement with Chandrakar's (2011) study, where chickens fed on a diet supplemented with $15 \mathrm{~g} / \mathrm{kg}$ had significantly increased monocyte cells. In this study, the heterophil to lymphocyte $(\mathrm{H} / \mathrm{L})$ ratio was significantly decreased $(p<0.05)$ at $1.5 \%$, and this is in agreement with Farag's (2013) study and in disagreement with Chandrakar's (2011), Jang's (2011), and Abadi and Andi's (2014)studies. The H/L ratio is a good indicator of the chicken's perception in its environment and the increased $\mathrm{H} / \mathrm{L}$ ratio indicates that the birds were under acute stress. Finally, the reasons for the poor performance and the bad effect on blood parameters at $3.5 \%$ than at $1.5 \%$ group can be due to a higher concentration of essential oil. This finding was supported by Lee et al. (2004) who reported that 4\% coriander was included in the diet, which might have been toxic for quails.

\section{Conclusion}

In this investigation, the supplementation of coriander seed powder at $1.5 \%$ to broiler diets had a positive impact on the dressing percentages without skin and hematobiochemical profiles of broiler chicken. Therefore, the beneficial effect of improving the health of broiler chicks is an indication that this herb can be utilized to replace antibiotics as growth promoters.

\section{Acknowledgments}

The authors express our gratitude to the Department of Physiology, Biochemistry and Nutrition, Faculty of Veterinary Medicine, University of Tripoli. We also extend sincere thanks to Al-Maraie Company for providing chicks and chicks' diet. Also to the sheep farm manager at the University of Tripoli for allowing us to use the farm facilities during the trail.

\section{Authors contribution}

Abdelfettah Shirif designed and supervised the study, and analyzed and interpreted the data, and also reviewed the manuscript. Mona Khubeiz carried out the experiments, drafted the manuscript, and revised and approved the manuscript.

\section{References}

Abadi, K.M.A. and Andi, M.A. 2014. Effects of using coriander(Coriandrum sativum L.), savory (Satureja hortensis L.) and dill (Anethum graveolens L.) herb powder in diet on performance and some blood parameters of broilers. Int. J. Biosci. 5, 95-103.

Abo Omar, J., Hejazi, A. and Badran, R. 2016. Performance of broilers supplemented with natural herb extract. Open J. Anim. Sci. 6, 68-74.

Abou-Elkhair, R., Ahmed, H.A. and Selim, S. 2014. Effects of black pepper (Piper Nigrum), turmeric powder (Curcuma Longa) and coriander seeds (Coriandrum sativum) and their combinations as feed additives on growth performance, carcass traits, some blood parameters and humoral immune. Asian-Australas J. Anim. Sci. 27, 847-854.

Al-Jaff, F.K. 2011. Effect of coriander seeds as diet ingredient on blood parameters of broiler chicks raised under high ambient temperature. Int. J. Poul. Sci. 10, 82-86.

Al-Mashhadani, E.H., Al-Jaff, F.K., Hamodi, S.J. and Al-Mashhadani, H.E. 2011. Effect of different levels of coriander oil on broiler performance and some physiological traits under summer condition. Pak. J. Nutr. 10, 10-14.

Amad, A.A., Männer, K., Wendler, K.R., Neumann, K. and Zentek, J. 2011. Effects of a phytogenic feed additive on growth performance and ileal nutrient digestibility in broiler chickens. Poult. Sci. J. 90, 2811-2816. 
AOAC. 1990. Offical methods of analysis, 15th ed. Washington, DC: Association of Official Agricultural Chemists.

Applegate, T.J., Klose, V., Steiner, T., Ganner, A. and Schatzmayr, G. 2010. Probiotics and phytogenics for poultry: myth or reality. J. Appl. Poult. Res. 19, 194-210.

Barad, N.A., Savsani, H.H., Patil, S.S., Garg, D.D., Das, O., Singh, V., Kalaria, V.A. and Chatrabhuji, B.B. 2016. Effect of feeding Coriander seeds, black pepper and turmeric powder as feed additives on hemato-biochmical profile and performance of broiler chicken. Int. J. Sci. Environ. 5, 3976-3982.

Brenes, A. and E. Roura. 2010. Essential oils in poultry nutrition: main effects and modes of action. Anim. Feed Sci. Technol. 158, 1-14.

Chandrakar, K. 2011. Evaluation of coriaderum sativum as an alternative to antibiotic growth promoter in broiler birds, Raipur, India: Chhattisgarh Kamdhenu Vishwavidyalaya, Thesis, pp: 37-57.

Dhanapakiam, P., Joseph, J.M., Ramaswamy, V.K., Moorthi, M. and Kumar, A.S. 2007. The cholesterol lowering property of coriander seeds (Coriandrum sativum): mechanism of action. J. Environ. Biol. 29, 53-56.

Esteghamat, O. 2014. An investigation on dietary supplementation of coriander (Coriandrum sativum) seeds on the food intake and microbial populations of the ceca of Japanese quail (Coturnix japonica). Biol. Forum 6(2), 53-56.

Farag, S.A. 2013. The efficiency of Coriander seeds as dietary additives in Broiler Chicken's diets. Egypt. J. Nutr. Feed 16, 491-501.

Ferket, P.R. and Gernat, A.G. 2006. Factors that affect feed intake of meat birds: a review. Int. J. Poult. Sci. 5, 905-911.

Ghazanfari, S., MohamedI, Z. and Adib, M,M. 2015. Effects of coriander essential oil on the performance, blood characteristics, intestinal microbiota and histological of Broilers. Braz. J. Poult. Sci. 17, 419-426.

Goering, H.K. and van Soest, P.J. 1970. Forage fiber analysis (apparatus reagents, procedures and some applications). Agriculture Handbook. Washington DC: United States Department of Agriculture.

Hady, M.M., Zaki, M.M., Wafaa, A.E. and Reda, M.S.K. 2016. Assessment of the broilers performance, gut healthiness and carcass characteristics in response to dietary inclusion of dried coriander, turmeric and thyme. Int. J. Environ. Agric. Res. 2, 153-159.

Hamodi, S.J., Al-Mashhadani, E.H., Al-Jaff, F.K. and Al-Mashhadani, H.E. 2010. Effect of coriander seed (Coriandrum sativum L.) as diet ingredient on broilers performance under high ambient temperature. Int. J. Poult. Sci. 9, 968-971.

Hashemi, S.R. and Davoodi, H. 2010. Phytogenics as new class of feed additive in poultry industry. J. Anim. Vet. Adv. 9, 2295-2304.
Jang, J.P. 2011. Effect of different levels of coriander oil on performance and blood parameters of broiler chickens. Ann. Biol. Res. 2, 578-583.

Lee, K.W., Everts, H. and Beynen, A.C. 2004. Essential oils in broiler nutrition. Int. J. Poult. Sci. 3, 738752.

Misharina, T. 2001. Effect of conditions and duration of storage on composition of essential oil from Coriander seeds. Prikl Biokhim Mikrobiol. 37, 726-732.

Nadeem, M., Muhammad Anjum, F., Issa Khan, M., Tehseen, S., El-Ghorab, A. and Iqbal Sultan, J. 2013. Nutritional and medicinal aspects of coriander (Coriandrum sativum L.) A review. Br. Food J. 115, 743-755.

Naeemasa, M., Alaw Qotbi, A.A., Seidavi, A., Norris, D., Brown, D. and Ginindza, M. 2015. Effects of coriander (Coriandrum sativum L.) seed powder and extract on performance of broiler chickens. South African J. Anim. Sci. 45(4), 372-378.

National Research Council (NRC). 1994. Nutrient Requirements of Poultry: Ninth Revised Edition, 1994. Washington, DC. The National Academies Press. https://doi.org/10.17226/2114.

Patel, K. and Vakilwala, M. 2016. Phytochemical study and bioactivity of solvent extracts on Coriandrum sativum. Int. J. Adv. Res. Biol. Sci. 3, 193-199.

Pathak, N.L., Kasture, S.B., Bhatt, N.M. and Rathod, J.D. 2011. Phytopharmacological properties of coriander sativum as a potential medicinal tree: an overview. J. Appl. Pharm. Sci. 1, 20-25.

Rahimi, S., Teymori Zadeh, Z., Torshizi, K., Omidbaigi, R. and Rokni, H. 2011. Effect of the three herbal extracts on growth performance, immune system, blood factors and intestinal selected bacterial population in broiler chickens. J. Agric. Sci. Tech. 13, 527-539.

Rashid, M.M., Ahammad, M.U., Ali, M.S., Rana, M.S., Ali, M.Y. and Sakib, N. 2014. Effect of different levels of Dhania seed (Coriandrum sativum) on the performance of broiler. Bangladesh J. Anim. Sci. $43,38-44$.

Saeid, J.M. and Al-nasr, A.S. 2010. Effect of dietary coriander seeds supplementation on growth performance. Int. J. Poult. Sci. 9(9), 867-870.

Saleh, A.A., Ijiri, D. and Ohtsuka, A. 2014. Effects of summer shield supplementation on growth performance, nutrient utilisation, and plasma lipid profiles in broiler chickens. Vet. Med. 11, 536-542.

Sambasivaraju, D. and Fazeel, Z. 2018. Evaluation of antibacterial activity of Coriandrum sativum (L.) against gram-positive and gram-negative bacteria. Int. J. Basic Clin. Pharmacol. 5, 2653-2656.

Shams, M., Esfahan, S.Z., Esfahan, E.Z., Dashtaki, H.N., Dursun, A. and Yildirim, E. 2016. Effects of climatic factors on the quantity of essential oil and dry matter yield of coriander (Coriandrum sativum L.). Indian J. Sci. Tech. 9, 1-4. 
Shoukary, R.D.E., Darwish, M.H.A. and AbdelRahman, M.A.M. 2017. Differential leucocyte count and total colony count changes in heat stressed broiler. J. Adv. Vet. Res. 5, 21-28.

Silva, F., Ferreira, S., Duarte, A., Mendonça, D.I. and Domingues, F.C. 2011. Antifungal activity of Coriandrum sativum essential oil, its mode of action against Candida species and potential synergism with amphotericin B. Phytomed. J. 19, 42-47. van Soest, P.J., Robertson, J.B. and Lewis, B.A. 1991 Method for dietary fiber, neutral detergent fiber, and non starch polysaccharides in relation to animal nutrition. J. Dairy Sci. 74, 3583-3597.

Zeb, A. 2016. Chapter 40 - coriander (Coriandrum sativum) oils A2 - Preedy, Victor R. Essential oils in food preservation, flavor and safety. San Diego, CA: Academic Press, pp: 359-364. 